\title{
THE INNOVATIVE DESIGN OF RECIPROCATING SEAL FOR HYDRAULIC CYLINDER BASED ON TRIZ EVOLUTION THEORY
}

\author{
Fuying Zhang, Hui Liu, Linjing Zhang \\ Department of Mechanical Engineering, Tianjin University of Science \& Technology, Tianjin \\ 300222, P.R.Chain;Email:zhfuying@tust.edu.cn
}

\begin{abstract}
The design of reciprocating seal is extra important to the hydraulic cylinder's performances at lower speed, sensitive, dynamic and static rigidity. Technology evolution of TRIZ provides the laws or prevailing lines of technology system evolution which a designer should follow to find the inventive solutions. To help a designer to get the innovative ideas in a short time by using TRIZ evolution theory and to make the innovative design process operable, a CAI software tool for gauging and positioning of the state of a system in relation to each law or line of technology system evolution is developed. It can draw the evolutionary potential radar plot of studied system automatically on the basis of evolution analysis. The innovative design of reciprocating seal for hydraulic cylinder is detailed according to the future possible development opportunities that evolutionary potential plot recommends.
\end{abstract}

Key words: Hydraulic cylinder; TRIZ technology evolution; reciprocating seal; evolutionary potential; CAI software tool

\section{INTRODUCTION}

The reciprocating seal is a key technology of hydraulic cylinder. The hydraulic cylinder's performances at lower speed, sensitive, dynamic and static rigidity depend more on the capability of the hydraulic reciprocating seal.

The reciprocating seal is built upon the theories of lubrication, tribology, wear, heat transfer, material properties, and structure design of sealing

This project is supported by The Science Research Fund of Tianjin University of Science \& Technology under the grant No.20050217.

Please use the following format when citing this chapter:

Zhang, Fuying, Liu, Hui, Zhang, Linjing, 2006, in International Federation for Information Processing (IFIP), Volume 207, Knowledge Enterprise: Intelligent Strategies In Product Design, Manufacturing, and Management, eds. K. Wang, Kovacs G., Wozny M., Fang M., (Boston: Springer), pp. 440-449. 
interface ${ }^{1}$. It is the most complex application situation and the most severe demand for dynamic seal in the hydraulic equipments. Therefore, it is important to develop new reciprocating seal technology by analyzing and evaluating the development potential of current sealing technologies in the aspect of structure, material, shape, and consequently to predict their possible future structure stage.

Technology evolution theory, which is special in technology predicting, is an important branch of TRIZ ${ }^{2}$ (The Theory of Inventive Problem Solving). Laws of technology system evolution are the theoretical fundament of TRIZ evolution theory. Presently, TRIZ technology evolution has different versions: evolution of technique ${ }^{3}$ (ET), guided technology evolution ${ }^{4}$, directed evolution ${ }^{5}$ (DE). TRIZ technology evolution does not predict the future of technology; it also forces the system to its most probable future development by inventing it before it would occur naturally. Designers can systematically generate the creative ideas necessary for developing a nextgeneration product or process by using technology evolution theory.

In this paper, the technology evolution of TRIZ is first reviewed. Then, using the CAI software tools in which TRIZ evolution theory forms the very basis, we present the future development directions of the reciprocating seal by analyzing its evolutionary course and the lines of evolution. Finally, the innovation design of reciprocating seal for hydraulic cylinder is carried out according to the recommendation of evolutionary potential plot.

\section{TRIZ TECHNOLOGY EVOLUTION THEORY}

Laws of technical systems evolution form the very basis of TRIZ. By the term law, Altshuller means a trend that governs the development of any technical system. However, it is not easy to use them in the perspective of product development. To make these laws operational in the design process, patterns/lines of technology evolution are summarized, and evolutionary potential of technical system are presented. These patterns/lines, and evolutionary potential plot can be easily understood and used by designers to get innovative product ${ }^{6}$.

\subsection{The evolution s-curve of technology system}

According to Altshuller, technology is always in evolution. As they evolve, most technologies follow predetermined patterns rather than representing a collection of random events. The evolution process of 
technology systems can be represented by the classic s-curve, which illustrates the life cycle stages of infancy, growth, maturity and decline.

TRIZ researchers discover that technological systems always tend to evolve in the direction of increased ideality. Fig.1 provides a generic graphical description of technology system evolution toward ideality through a family of S-curves. With this chart, we are able to forecast that there always will be a future technology development that will replace current technology - a very powerful and insightful knowledge indeed. We should make current technology jump to the next-generation S-curve by eliminating the inherent conflicts of technology systems, when it reaches the limitation of its performance.

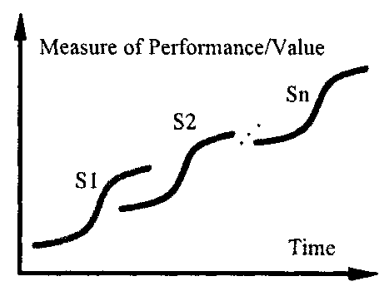

Figure 1. Evolution S-curve of technology systems

\subsection{Patterns/ lines of technology system evolution}

The patterns of evolution represent a compilation of trends that document strong historically recurring tendencies in the development of manmade or natural systems. There were three different versions about the patterns of evolution since the work was first published, such as Altshuller's ten set of patterns ${ }^{2}$, Zusman's eight set of patterns ${ }^{7}$ and Darrell's eleven set of patterns ${ }^{6}$. In our software tool, Darrell's eleven set of patterns of technological evolution are used to summarize the evolution of technology systems. These trends describe evolution towards:

- Pattern.1: Systems with increasing benefits and decreasing cost and harm.

- Pattern.2: Increased dynamization within systems.

- Pattern.3: Increased system segmentation.

- Pattern.4: Increased space segmentation.

- Pattern.5: Increased surface segmentation.

- Pattern.6: Increased controllability.

- Pattern.7: Increased complexity followed by reduced complexity.

- Pattern.8: Use of all available physical dimensions within a system.

- Pattern.9: Decreased number of energy conversions.

- Pattern.10: Increased rhythm co-ordination.

- Pattern.11: Increased action co-ordination. 
Every pattern of technology evolution includes many lines of evolution ${ }^{8}$. In each line of evolution, researchers have identified a number of generic evolution steps up to and including a final level of evolutionary potential. The study of lines of technology evolution can provide ideas for technology systems' jumping to next-generation. The current state of the art now brings the total number of technical evolution lines to over $300^{8}$. It is significant for product innovation to study the evolution lines.

\subsection{Evolutionary potential of technical system}

The patterns/lines of evolution and their incorporation into a design method generate the new concept of evolutionary potential ${ }^{6}$. Evolutionary potential radar plot is illustrated in Fig.2. Each spoke in the plot represents one of the TRIZ patterns relevant to the given component .The outside perimeter of the plot represents evolutionary limit, and the shaded area represents how far along each pattern the current system has evolved. Thus the area difference between shaded area and perimeter is a measure of evolutionary potential. The counts of evolutionary patterns covered in evolutionary potential radar plot are different for different products. Evolutionary potential radar plot is used as a way of describing how far along each of the TRIZ patterns a given system has evolved, and is as powerful guides to help determining the future development opportunities and limits for a wide variety of technical systems.

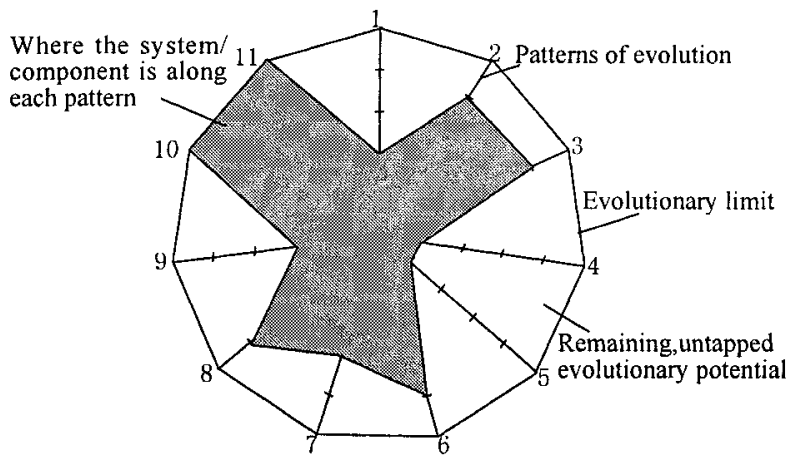

Figure 2. Evolutionary potential radar plot 


\section{THE EVOLUTION ANALYSIS OF RECIPROCATING SEAL FOR HYDRAULIC CYLINDER}

Reciprocating seals have various kinds with the difference in pressure and speed of liquid, dimensions of radial and axis, and the property of dynamic and static of hydraulic cylinder. In this paper, the reciprocating seal we will discuss is focused on the development of seal, and is not a restriction of detail hydraulic elements.

\subsection{Evolution S-curve of reciprocating seal}

Lack of space dictates, the reciprocating seal's evolution s-curve given by CAI software tool is shown in Fig. 3. It is the result of the quantitative analysis of reciprocating seal's performances at material, configuration, controllable, wear and scuffing. Obviously, the reciprocating sealing is still positioned at the growth stage of its evolution curve and the future development opportunity of hydraulic reciprocating sealing technology will increase the seal, wear and scuffing characteristics by improving the configuration, material and shape.

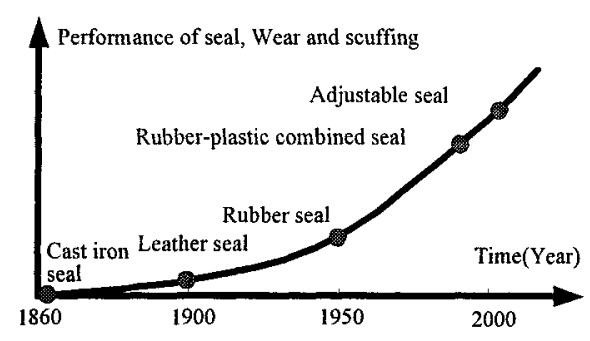

Figure 3. The evolution S-curve of reciprocating seal

\subsection{Evolution lines of hydraulic reciprocating seal}

In order to find a point along the trend that best describes the current evolutionary state of the reciprocating seal design, we compare reciprocating seal design with each of the Darrell's evolution patterns, and summarize its evolution lines. The evolution states of existing reciprocating seal are shown in Fig.4. Table 1 presents the general evolution lines which are discovered by TRIZ researcher based on the study and application of the patterns of 
evolution in various systems and are closely relevant to the evolution of reciprocating seal.

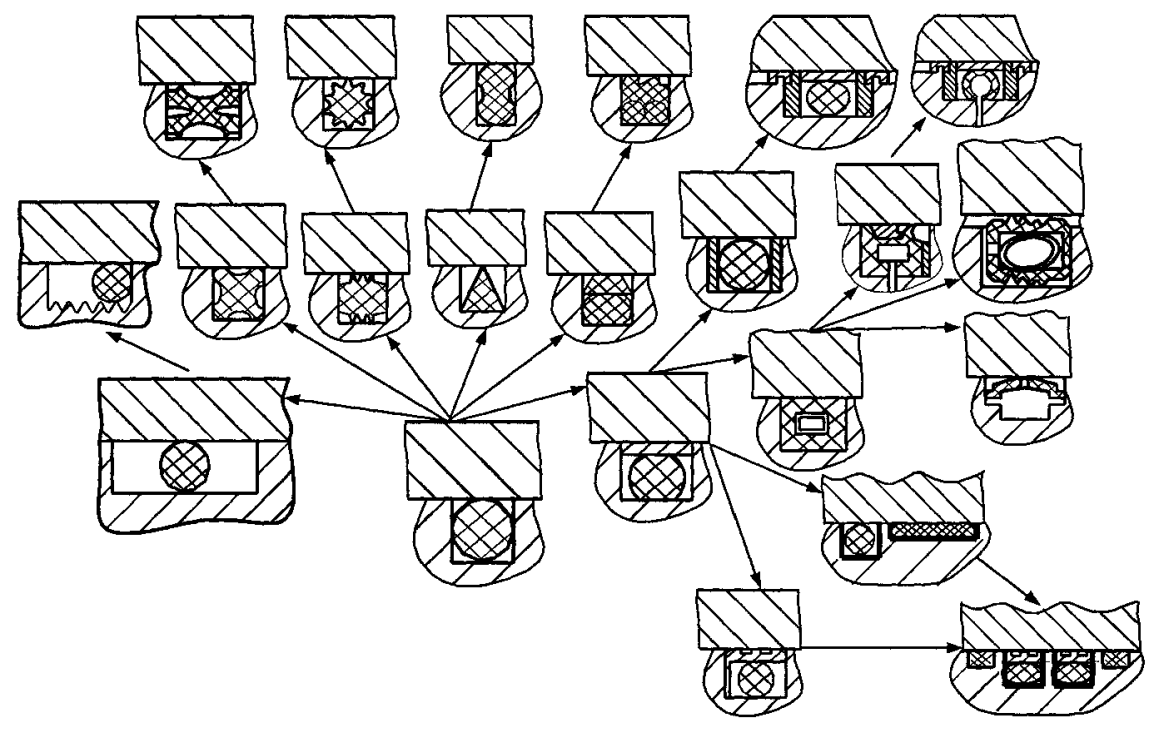

Figure 4. Evolution states of reciprocating seal

Table 1. The general evolution lines closely relevant to the evolution of reciprocating seal

Darrell's The general lines of evolution The lines of evolution of reciprocating evolution seal

patterns

Pattern $1 \quad$ Dear material $\rightarrow$ general material $\rightarrow$

Rubber seal $\rightarrow$ synthetic rubber seal $\rightarrow$ compound material $\rightarrow$ function material.

Pattern 2 Immobile system $\rightarrow$ joint $\rightarrow$ many joints $\rightarrow$ completely elastic $\rightarrow$ liquid, gas $\rightarrow$ field.

Mono-system $\rightarrow$ Bi-system $\rightarrow$ Three system $\rightarrow$ poly-system $\rightarrow$ combined poly-system. synthetic rubber seal with wearable additive.

O-ring seal $\rightarrow$ magnetic liquid seals $\rightarrow$ magnetic seals.

Mechanical field $\rightarrow$ hydraulic field $\rightarrow$ electromagnetic field $\rightarrow$ chemic field $\rightarrow$ biologic field.

Single field $\rightarrow$ combined field with two-field $\rightarrow$ combined field with multi-field.

Pattern $3 \quad$ System $\rightarrow$ segmental monolith $\rightarrow$ liquid or powder $\rightarrow$ gas $\rightarrow$ field.

Combined coaxial seal $\rightarrow$ O-ring seal with backup-rings $\rightarrow$ combined coaxial seal with backup-ring and bearings.

Elasticity seal $\rightarrow$ spring elasticity seal $\rightarrow$ liquid elasticity seal.

Rubber seal $\rightarrow$ plastic and spring seal $\rightarrow$ plastic, spring and liquid seal.

Single O-ring seal $\rightarrow$ two-ring seal $\rightarrow$ three-ring seal. 


\begin{tabular}{|c|c|c|}
\hline $\begin{array}{l}\text { Darrell's } \\
\text { evolution } \\
\text { patterns }\end{array}$ & The general lines of evolution & $\begin{array}{l}\text { The lines of evolution of reciprocating } \\
\text { seal }\end{array}$ \\
\hline Pattern 4 & $\begin{array}{l}\text { Mono-system } \rightarrow \text { system with a cavity } \\
\rightarrow \text { system with multiple cavity } \\
\rightarrow \text { capillary and porous system } \\
\rightarrow \text { system with active capillary }\end{array}$ & $\begin{array}{l}\text { Combined coaxial seal } \rightarrow \text { coaxial seal } \\
\text { with oil grooves to form } \\
\text { hydrodynamic lubrication. }\end{array}$ \\
\hline Pattern 5 & $\begin{array}{l}\text { Flat surface } \rightarrow \text { surface with single } \\
\text { protrusion } \rightarrow \text { surface with two- } \\
\text { protrusion } \rightarrow \text { rough surface } \rightarrow \\
\text { combined surface. }\end{array}$ & $\begin{array}{l}\text { O-ring seal } \rightarrow \text { multi-grooved surface } \\
\text { seal } \rightarrow \text { grooved surface seal. }\end{array}$ \\
\hline Pattern 6 & $\begin{array}{l}\text { Direct control action } \rightarrow \text { action though } \\
\text { intermediary } \rightarrow \text { addition of feedback } \\
\rightarrow \text { intelligent feedback. }\end{array}$ & $\begin{array}{l}\text { Elasticity unalterable combined seal } \\
\text { with PTFE and spring } \rightarrow \text { PTFE seal } \\
\text { with liquid-loaded elasticity } \rightarrow \text { coaxial } \\
\text { seal with back-up rings, bearings and } \\
\text { adjustable elasticity by external liquid }\end{array}$ \\
\hline Pattern 7 & $\begin{array}{l}\text { Single function } \rightarrow \text { multi-function } \\
\rightarrow \text { integrated function. }\end{array}$ & $\begin{array}{l}\text { O-ring seal } \rightarrow \text { Tandem seal with } \\
\text { different components to deliver } \\
\text { functions of seal and wearable } \\
\rightarrow \text { Tandem seal with different } \\
\text { components to deliver functions of } \\
\text { seal and wearable, while grooves form } \\
\text { hydrodynamic lubrication. }\end{array}$ \\
\hline \multirow[t]{2}{*}{ Pattern 8} & $\begin{array}{l}\text { Line } \rightarrow 2 \mathrm{D} \text {-curve } \rightarrow 2 \mathrm{D} \text {-curve } \rightarrow \\
\text { compound 3D-curve. }\end{array}$ & O-ring seal $\rightarrow$ anti-twist $X$-seal. \\
\hline & $\begin{array}{l}\text { Plane } \rightarrow \text { single curvature of surface } \\
\rightarrow \text { double curvature of surface } \rightarrow \\
\text { combined curvature of surface. }\end{array}$ & $\begin{array}{l}\text { O-ring seal } \rightarrow \text { triangle-ring seal } \rightarrow \\
\text { abnormity-ring seal. }\end{array}$ \\
\hline Pattern 9 & $\begin{array}{l}\text { Sliding friction } \rightarrow \text { combined friction } \\
\text { with sliding and rolling } \rightarrow \text { rolling } \\
\text { friction } \rightarrow \text { fluid friction }\end{array}$ & $\begin{array}{l}\text { O-ring seal } \rightarrow \text { O-ring seal with a free } \\
\text { seal chamber } \rightarrow \text { O-ring seal with } \\
\text { grooved in the seal chamber }\end{array}$ \\
\hline Pattern 10 & $\begin{array}{l}\text { Continuous action } \rightarrow \text { pulsation } \\
\text { action } \rightarrow \text { pulsation in the resonance } \\
\text { mode } \rightarrow \text { several actions } \rightarrow \text { travelling } \\
\text { wave }\end{array}$ & $\begin{array}{l}\text { O-ring seal } \rightarrow \text { continuous seal in } \\
\text { bidirectional } \rightarrow \text { one direction seal } \\
\text { discontinuous }\end{array}$ \\
\hline Pattern 11 & $\begin{array}{l}\text { Non-coordinated actions } \rightarrow \text { partially } \\
\text { coordinated actions } \rightarrow \text { coordinated } \\
\text { actions } \rightarrow \text { actions during intervals }\end{array}$ & $\begin{array}{l}\text { Tandem seal of PTFE and O-ring } \\
\rightarrow \text { Combined coaxial seal }\end{array}$ \\
\hline
\end{tabular}

In all the evolution lines being presented, TRIZ depicts an evolutionary progression from left to right across each trend, in which benefits increase as a design travels further rightwards. 


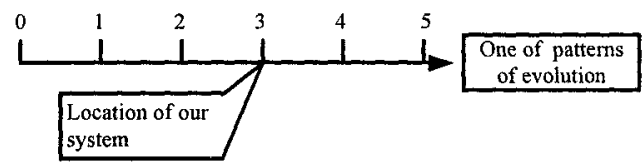

Figure 5. The process of positioning a system in relation to the patterns of evolution

\section{THE INNOVATIVE DESIGN OF RECIPROCATING SEAL FOR HYDRAULIC CYLINDER USING CAI SOFTWARE TOOLS}

\subsection{The method of gauging and positioning the state of a system in relation to patterns of evolution}

The main difficult encountered in procedure of making the patterns or lines of evolution operational is the gauging and positioning of the state of a system in relation to each pattern or lines of evolution ${ }^{9}$. In our CAI software tools, we use the fuzzy sets to gauge the relative evolutionary position of system. Fig. 5 shows the process of positioning the system in relation to a pattern of evolution. The meaning of fuzzy value $0,1,2,3,4$ and 5 is presented in Table 2.

Table 2. Positioning a system in relation to the patterns

\begin{tabular}{ll}
\hline Fuzzy value & The meaning of value \\
\hline 0 & The pattern is not applied at all, it is necessary to focus on its development \\
\hline 1 & $\begin{array}{l}\text { The pattern is applied to a small extent, the future development of the system } \\
\text { probably depends on developing this pattern }\end{array}$ \\
\hline 3 & $\begin{array}{l}\text { In most cases, the pattern is applied; it would nonetheless be useful to observe } \\
\text { a development in this direction if no other pattern is really deficient. }\end{array}$ \\
\hline 5 & $\begin{array}{l}\text { The pattern is applied to the latter, a development in this direction is probably } \\
\text { not what is most urgently needed in the system's development overall }\end{array}$ \\
\hline 2,4 & Intervenient of 0 and 1,3 and 5 \\
\hline
\end{tabular}

\subsection{Positioning the reciprocating seal in relation to the patterns of evolution}

According to table 2, we can position the reciprocating seal in relation to the patterns of evolution. Lack of space dictates the details positioning process of the reciprocating seal in relation to each pattern of Darrell's evolution, the contents is omitted in this paper. The detail process can reference paper 10 . 


\subsection{Evolution potential plots of hydraulic reciprocating seal}

Fig.6 presents the evolutionary potential plot. The plot clearly shows that there to be considerable amounts of untapped potential in the reciprocating design, such as the potential to improve the ability of adjustable of the system and to increase the segments of configuration, shape, highlighting the utility of systems resource. Therefore, there are consequently significant improvements for reciprocating seal design, if we explore all abovementioned untapped potential.

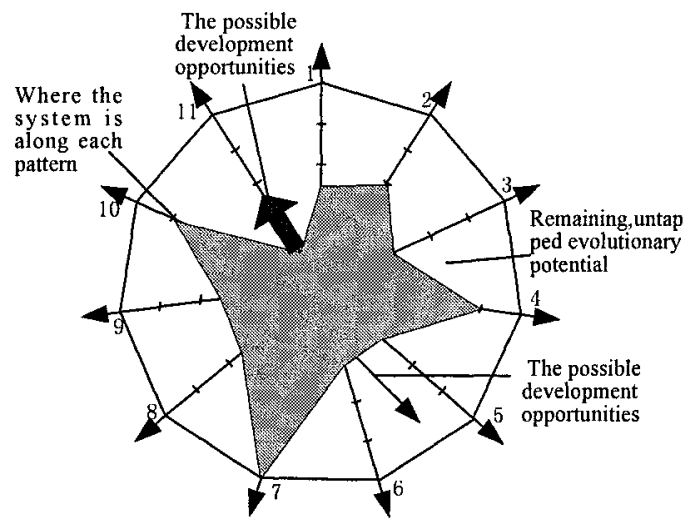

Figure 6. Evolutionary potential radar plot of hydraulic reciprocating seal technology

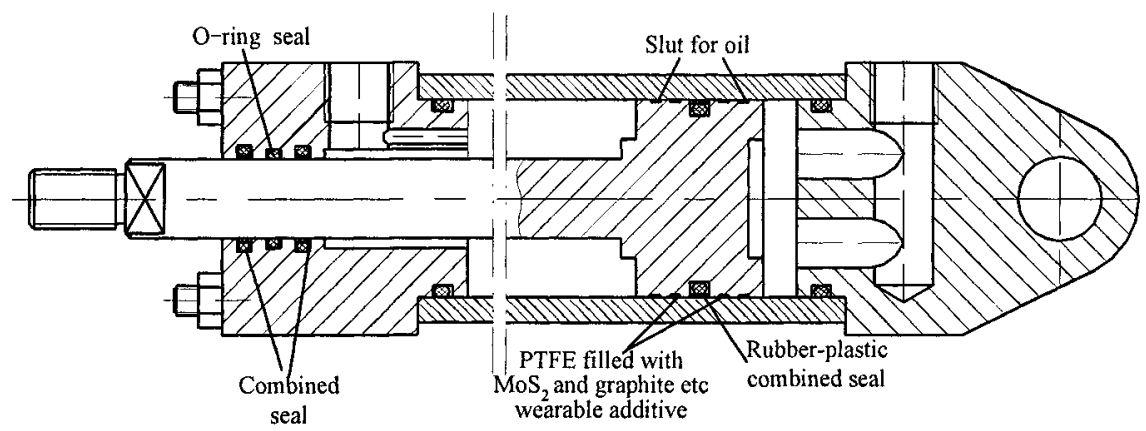

Figure 7. Reciprocating seal design for hydraulic cylinder 


\subsection{The innovative design of reciprocating seal using TRIZ}

On the Basis of our work and the result of evolutionary potential radar plot, we present the detail design of reciprocating seal for hydraulic cylinder in Fig.7.

\section{CONCLUSIONS}

Traditional product development is based on the principle that everything is feasible in terms of the thought process, and encourages reflections from every angle and potentially leads people in a broad spectrum of directions. CAI software tools based on TRIZ evolution theory provide a powerful structure methodology to guide designers closer to the right solution. In this paper, by using CAI software tool, we position the evolution stage of reciprocating seal in its evolution S-curve and draw its evolutionary potential radar plot. Making use of the possible development opportunities that are recommended by evolutionary potential radar plot, we detail the innovative design of reciprocating seal for hydraulic cylinder.

\section{REFERENCES}

1. Mnler,H.K. and Nau,B.S., Fluid sealing technology-principles and applications (China Machine Press, Beijing, 2002).

2. G.S.Altshuller, Creativity as an Exact Science(Gordon \& Breach, New York, 1988).

3. Savransky S D, Engineering of creativity (CRC Press, New York, 2000).

4. Fey V R, Rivin EI, Guided technology evolution-TRIZ technology forecasting (1999); http://www.triz-journal.com/article2.html.

5. Zusman A, Zlotin B and Zainiev G, An application of directed evolution (2003); http://www.ideationtriz.com/Endoscopic_case_study.asp.

6. Mann, D.L, Better technology forecasting using systematic innovation methods, Technological Forecasting and Social Change.Vol.70, pp.779-795(2003).

7. B.Zlotin, A.Zusman: Directed Evolution: Philosophy, Theory and Practice (Ideation International Inc, USA, 2001).

8. S.R.Luke, A Conceptual Design Tool for Engineers: An Amalgamation of Theory of Constraints, theory of Inventive Problem Solving and Logic (Old Dominion University ,U.K.2002).

9. Cavallucci D Integrating Altshuller's development laws for technical systems into the design process, Annals of the CIRP, Vol.52(1),(2002)

10. Zhang Fuying, Xu Yanshen, Evolution study of hydrodynamic reciprocating sealing for hydraulic cylinder based on TRIZ, Run Hua Yu Mi Feng/ Lubrication Engineering, Vol.163,pp.14-17 (2004). 